\title{
EXTENDED FINITE ELEMENT MODELLING OF ADHESIVE JOINTS UNDER PEEL LOADS
}

\author{
F. J. P. Moreiral, R. D. S. G. Campilho2* \\ ${ }^{1}$ Departamento de Engenharia Mecânica, Instituto Superior de Engenharia do Porto, Instituto Politécnico do \\ Porto, R. Dr. António Bernardino de Almeida, 431, 4200-072 Porto, Portugal \\ ${ }^{2}$ INEGI - Pólo FEUP, Rua Dr. Roberto Frias, 400, 4200-465 Porto, Portugal \\ *Corresponding author's e-mail address: raulcampilho@gmail.com
}

\begin{abstract}
The use of adhesive bonds greatly increased in industrial applications, as they have multiple advantages compared to other more traditional bonding methods (fastened, welded and riveted joints). The number of approaches to predict the strength of adhesive joints has increased over the years. The eXtended Finite Element Method (XFEM) is a recent variant of the (Finite Element Method) FEM to model damage growth in structures, although it is yet seldom studied within the context of bonded joints. This work consists of an experimental and XFEM analysis of aluminium alloy T-joints, adhesively-bonded with three adhesive types. A parametric study is undertaken regarding the curved adherends' thickness $\left(t_{\mathrm{P} 2}\right)$, with values between 1 and $4 \mathrm{~mm}$. The adhesives Araldite ${ }^{\circledR}$ AV138, Araldite 2015 and the Sikaforce ${ }^{\circledR} 7752$ were tested. A comparative analysis between the different joints conditions was performed, too. The XFEM predictive capabilities were tested with different damage initiation criteria. It was found that, provided that the modelling conditions are properly set, accurate numerical results can be found.
\end{abstract}

KEYWORDS: Fracture, Finite element analysis, eXtended Finite Element Method, Bonded joint.

\section{INTRODUCTION}

The use of adhesive bonds greatly increased in industrial applications, as they have multiple advantages compared to other more traditional bonding methods (fastened, welded and riveted joints). The aeronautical, naval, automotive and aerospace industries are good examples where adhesive joints are widely applied. More uniform distribution of stresses, ease of manufacture, possibility of joining different materials and low cost are the main advantages of adhesive bonds. The main disadvantages are related to the requirement of surface preparation, low peel strength and difficulties in quality control and safety. The most common adhesive joint configurations are single-lap joints (SLJ), double-lap joints (DLJ) and scarf joints [1]. SLJ are the most common. However, they develop major $\square$ y peak stresses. DLJ are more difficult to manufacture but, on the other hand, $\square$ y stresses greatly diminish. Scarf joints are highly efficient when compared to SLJ because of the reduction of stress concentrations [1]. Although these types of joints are the most used in the industry, other types of joints have specific applications. Stepped-lap configurations can be used in composite joining due to the easiness to make the step design during the materials' fabrication process [2]. T-joints find application in the naval and aeronautical industries. In the naval industry, they allow joining panels with the hull [3] and the fiberglass hull with anti-flood panels [4]. In the aeronautical industry, they are used to join wing panels and fuselage sections [5]. Several works were carried out to evaluate T-joints, using either analytical or numerical techniques [6], [7].

The number of approaches to predict the strength of adhesive joints has increased over the years. Actually, analytical and numerical techniques have become more and more refined and with higher accuracy. Numerical methods are typically founded on the FEM. The FEM allows modelling complex geometries with high precision, due to the computational advancements and Computer Aided Engineering (CAE) tools. Within this scope, the use of Continuum Mechanics supposes using the obtained stresses or strains, whose maximum values are used in appropriate failure criteria to assess failure. However, this technique has limited applicability because of stress singularities (which make the predictions dependent on the applied mesh) and because it neglects fracture mechanics concepts [8]. Actually, in a bonded joint FEM analysis, stresses near the 
singular regions increase with the mesh refinement, making convergence impossible [9]. Traditional Fracture Mechanics-based techniques can be applied to the study of the behaviour of structures that contain defects, such as cracks. These cracks can result from stress concentrations, usually located in holes, notches or interfaces between different materials. However, it is not mandatory that the structures to be analysed already have cracks, which is a limitation of this method [10]. Cohesive Zone Models (CZM) were developed to describe damage under static loads in the cohesive process zone around the crack tip. They are based on cohesive elements, which allow connecting solid elements of two-dimensional (2D) and three-dimensional (3D) structures, using preestablished traction-separation laws [11]. The use of CZM to model structures enables to create one or more regions or interfaces in which damage nucleation and growth is made possible by the softening and release of homologous nodes of the cohesive elements [12]. FEM simulations based on continuum mechanics wrongly consider that the solid elements undergo plasticization without taking damage. Damage mechanics simulations work by inducing damage to the elements through the reduction of transmitted loads between solid elements. Thus, it is possible to perform the simulation of crack growth, in which the cracks can assume a pre-defined trajectory or an arbitrary trajectory within a finite region [8]. In Damage Mechanics, a damage parameter is established to cause a change in the response of the constituent materials through the depreciation of the strength or stiffness, as occurs in adhesive layers, or in composite delaminations, to model damage during loading [13], [14]. The insertion of a damage variable in the constitutive law of the material enables simulating damage before and after crack nucleation. The growth of damage is usually ruled by the load function for static simulations [16] and as a function of the number of cycles for fatigue modelling [17], [18]. The XFEM is a recent variant of the FEM to model damage growth in structures, although it is yet seldom studied within the context of bonded joints. This method uses damage laws to predict fracture, based on strength concepts to infer damage initiation of damage and deformations for failure. Comparing the XFEM to CZM, the XFEM has the clear advantage of not requiring the crack to follow a predefined path by the user. This is because crack propagation occurs freely inside the material, without the geometry of the discontinuities being coincident with the mesh or the necessity to correct the mesh in the crack vicinity [19]. The XFEM is based on the concept of partition of unity, and its implementation in the FEM can be accomplished by introducing local enrichment functions for the displacements near the crack tip, allowing damage to grow and respective separation between the cracked faces [20]. Mubashar et al. [21] carried out a study on the damage and failure modelling of adhesively-bonded SLJ with spew fillets at the overlap ends, combining two methods: XFEM (to perform the modelling of the crack in the fillet region where the crack path is unknown) and CZM (applied to model crack progression and damage along the adhesive bond interface). The numerical analysis was performed in Abaqus ${ }^{\circledR}$. Aluminium alloy 2024 T3 adherends were bonded with the epoxy adhesive FM73-M. It was concluded that the XFEM is capable of predicting, with a high degree of precision, the crack onset location and path within the spew fillet. Stuparu et al. [22] conducted a study on the combined use of CZM and XFEM for the strength prediction of bonded joints. The SLJ configuration was tested, with aluminium adherends and the adhesive Araldite ${ }^{\circledR}$ AV138. The following parameters were used: adherends' thickness $\left(t_{\mathrm{P}}\right)$ of $5 \mathrm{~mm}$, adhesive thickness $\left(t_{\mathrm{A}}\right)$ of 1,3 and $5 \mathrm{~mm}$, overlap length $\left(L_{O}\right)$ of $20 \mathrm{~mm}$ and sample width $(B)$ of $25 \mathrm{~mm}$. The XFEM was used to simulate failure within the adhesive, considering a strain criterion (less mesh dependent than stress criteria) for crack onset prediction. Thus, crack initiation/propagation will always take place orthogonally to the maximum principal strains. On the other hand, CZM was equated to simulate an interfacial failure between the adhesive and adherends. Different $t_{\mathrm{A}}$ and the positions of initial bonding flaws were tested, resulting in modifications of the XFEM crack trajectories, eventually attaining the interface. It was shown that the use of XFEM is well complemented by CZM to promote crack growth after the XFEM crack attained the interface.

This work consists of an experimental and XFEM analysis of aluminium alloy $\mathrm{T}$-joints, adhesivelybonded with three adhesive types. A parametric study is undertaken regarding $t_{\mathrm{P} 2}$, with values between 1 and $4 \mathrm{~mm}$. The adhesives Araldite ${ }^{\circledR}$ AV138 (strong but brittle), Araldite ${ }^{\circledR} 2015$ (less strong but moderately ductile) and Sikaforce ${ }^{\circledR} 7752$ (with the smallest strength but highly ductile) were tested. A comparative analysis between the different joints conditions was undertaken. The XFEM predictive capabilities were tested with different damage initiation and propagation criteria.

\section{EXPERIMENTAL WORK}

\subsection{Joint Materials}

The T-joints are made of three AW6082 T651 aluminium alloy aluminium adherends bond together. This is a high-strength alloy, characterized in a previous work [23]. Figure 1 shows typical stressstrain $(\sigma-\varepsilon)$ curves of this aluminium alloy, whose relevant properties in bulk tensile testing are: Young's modulus $(E)$ of $70.1 \pm 0.8 \mathrm{GPa}$, tensile yield stress $\left(\sigma_{\mathrm{y}}\right)$ of 261.7 $\pm 7.7 \mathrm{MPa}$, tensile strength $\left(\sigma_{\mathrm{f}}\right)$ of $324.0 \pm 0.2$ $\mathrm{MPa}$ and tensile failure strain $\left(\varepsilon_{\mathrm{f}}\right)$ of $21.7 \pm 4.2 \%$. 


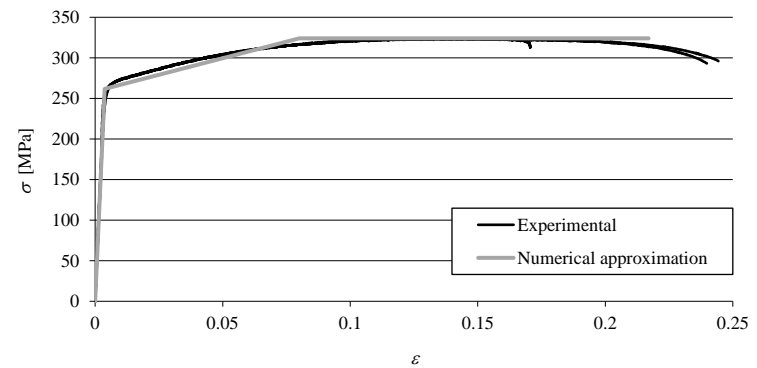

Fig. 1. Experimental and numerical $\sigma-\varepsilon$ curves of aluminium

The following adhesives were tested in the $\mathrm{T}$ joint configuration: Araldite ${ }^{\circledR}$ AV138 (brittle epoxy), Araldite $^{\circledR} 2015$ (ductile epoxy) and Sikaforce ${ }^{\circledR} 7752$ (high-elongation polyurethane). All adhesives were formerly tested and the respective properties detailed in references [23] - [25]. The tensile mechanical properties $\left(E, \sigma_{\mathrm{y}}, \sigma_{\mathrm{f}}\right.$ and $\left.\varepsilon_{\mathrm{f}}\right)$ resulted from bulk tests to dogbone specimens. The shear mechanical properties (Shear modulus $-G$, shear yield stress $-\tau_{\mathrm{y}}$, shear strength $-\tau_{\mathrm{f}}$ and shear failure strain $-\gamma_{\mathrm{f}}$ ) were estimated by Thick Adherend Shear Tests (TAST). The TAST specimens were made with DIN Ck 45 steel adherends, and curing was undertaken in a rigid mould to guarantee that the cured specimens are aligned [26]. The toughness properties of the adhesives were estimated with the Double-Cantilever Beam $(\mathrm{DCB})$ test (tensile fracture toughness or $G_{\mathrm{IC}}$ ) and the End-Notched Flexure (ENF) test (shear fracture toughness or $G_{\text {IIC }}$ ). Table 1 gives an overview of the obtained data, which will be used in this work for input in the numerical simulations. To be noted that the values of yield stress were defined considering a plastic strain of $0.2 \%$.

Table 1. Properties of the adhesives Araldite ${ }^{\circledR}$ AV138, Araldite ${ }^{\circledR} 2015$ and Sikaforce ${ }^{\circledR} 7752$ [23]-[25]

\begin{tabular}{lccc} 
Property & AV138 & $\mathbf{2 0 1 5}$ & $\mathbf{7 7 5 2}$ \\
\hline Young's modulus, $E[\mathrm{GPa}]$ & $4.9 \pm 0.8$ & $1.9 \pm 0.2$ & $0.5 \pm 0.1$ \\
Poisson's ratio, $v$ & $0.35^{\mathrm{a}}$ & $0.33^{\mathrm{a}}$ & $0.30^{\mathrm{a}}$ \\
Tensile yield stress, $\sigma_{\mathrm{y}}[\mathrm{MPa}]$ & $36.5 \pm 2.5$ & $12.6 \pm 0.6$ & $3.2 \pm 0.5$ \\
Tensile failure strength, $\sigma_{\mathrm{f}}[\mathrm{MPa}]$ & $39.5 \pm 3.2$ & $21.6 \pm 1.6$ & $11.5 \pm 0.3$ \\
Tensile failure strain, $\varepsilon_{\mathrm{f}}[\%]$ & $1.2 \pm 0.1$ & $4.8 \pm 0.8$ & $19.2 \pm 1.4$ \\
Shear modulus, $G[\mathrm{GPa}]$ & $1.6 \pm 0.01$ & $0.6 \pm 0.2$ & $0.2 \pm 0.01$ \\
Shear yield stress, $\tau_{\mathrm{y}}[\mathrm{MPa}]$ & $25.1 \pm 0.3$ & $14.6 \pm 1.3$ & $5.2 \pm 1.1$ \\
Shear failure strength, $\tau_{\mathrm{f}}[\mathrm{MPa}]$ & $30.2 \pm 0.4$ & $17.9 \pm 1.8$ & $10.2 \pm 0.6$ \\
Shear failure strain, $\gamma_{\mathrm{f}}[\%]$ & $7.8 \pm 0.7$ & $43.9 \pm 3.4$ & $54.8 \pm 6.4$ \\
Toughness in tension, $G_{\mathrm{IC}}[\mathrm{N} / \mathrm{mm}]$ & $0.20^{\mathrm{b}}$ & $0.4 \pm 0.02$ & $2.4 \pm 0.2$ \\
Toughness in shear, $G_{\mathrm{IIC}}[\mathrm{N} / \mathrm{mm}]$ & $0.38^{\mathrm{b}}$ & $4.7 \pm 0.3$ & $5.4 \pm 0.5$ \\
\hline${ }^{\mathrm{a}}$ manufacturer's data & & & \\
${ }^{\mathrm{b}}$ estimated in reference $[23]$ & & &
\end{tabular}

\subsection{Joint Fabrication and Testing}

Figure 2 represents the geometry and dimensions of the T-joints. The dimensions are: $L_{\mathrm{O}}=25 \mathrm{~mm}, B=25$ $\mathrm{mm}$, base length $L_{\mathrm{T}}=80 \mathrm{~mm}$, base thickness $t_{\mathrm{P} 1}=3 \mathrm{~mm}$,
$t_{\mathrm{P} 2}=1,2,3$ and $4 \mathrm{~mm}$, L-part length $L_{\mathrm{A}}=60 \mathrm{~mm}$, L-part radius $R=5 \mathrm{~mm}$ and $t_{\mathrm{A}}=0.2 \mathrm{~mm}$.

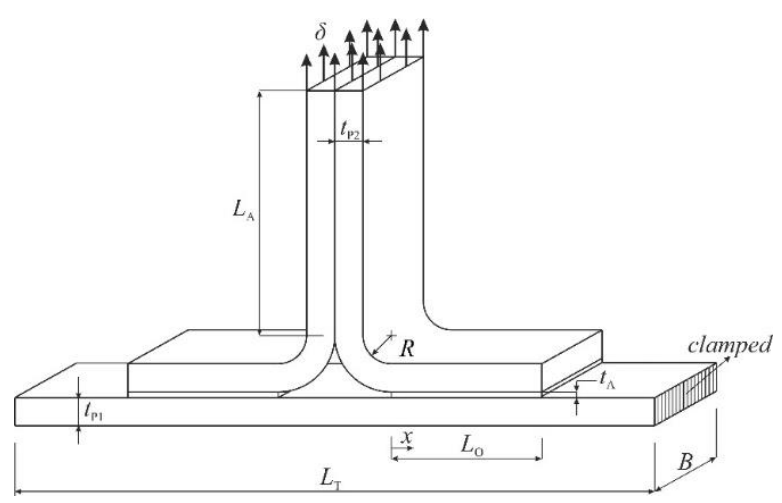

Fig. 2. Representative geometry and dimensions of the T-joints

Specimen fabrication was initiated by cutting/bending the adherends to the respective shapes. The straight adherend, used as the specimen base, is obtained by cutting. The L-parts were subjected to an identical procedure, but then they were manually bent in a press applying a tool with the chosen $R$, to produce the geometry depicted in figure 2 . The surface preparation before bonding consisted of sanding using emery paper with coarse grain (60 grit), followed by wiping with cleaning agent (acetone). The joining of the different parts was accomplished in a jig that positioned the three adherends in the layout of figure 2. To assure the specified $t_{\mathrm{A}}$, steel spacers with identical thickness to $t_{\mathrm{A}}$ were inserted at the edges of the bonded parts and were removed after adhesive curing. Before placing the spacers, they were initially coated with Loctite ${ }^{\circledR}$ Frekote $770 \mathrm{NC}$ demoulding agent. With the specimens in position, grips were used to apply pressure to the set and enable curing to take place during a one-week period. The final step consisted of trimming the excess cured adhesive by milling. As a result of this set of operations, it was possible to obtain a good representation of the theoretical geometry of figure 2, with emphasis to the bondline end geometry positioned at $x / L_{O}=0$ ( $x$ is the horizontal coordinate initiating at the bondline end). The specimens were tested as depicted in figure 2, i.e. by clamping the edges of the straight adherend and pulling in peel while transversely restraining the upper joint edge. This was done in a Shimadzu AG-X 100 testing machine, equipped with a $100 \mathrm{kN}$ load cell, at an approximate temperature of $20^{\circ} \mathrm{C}$ and with a testing speed of $1 \mathrm{~mm} / \mathrm{min}$. Five specimens were fabricated and tested for each joint type.

\section{NUMERICAL WORK}

\subsection{Modelling Conditions}

The analysis performed in Abaqus $^{\circledR}$ was 2D, considering a geometrically non-linear FEM 
formulation. The aluminium adherends (both base and L-parts) were modelled as solids with the plastic behaviour defined in a previous work for the same material [27]. The adhesive layer was also modelled with solid elements, but with enriched XFEM formulation. The XFEM model is presented in the next Section. In all cases, 4-node solid elements with plane-strain conditions were used (with Abaqus ${ }^{\circledR}$ reference CPE4). A relatively coarse mesh was considered to promote the XFEM failure analysis. Figure 3 shows the mesh refinement for a T-joint with $t_{\mathrm{P} 2}=1 \mathrm{~mm}$, with details at the loaded overlap edge.

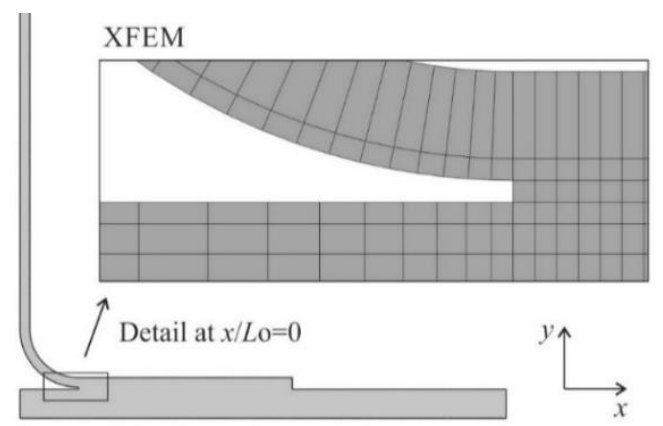

Fig. 3. Mesh at $x / L_{O}=0$ for the joint with $t_{\mathrm{P} 2}=1 \mathrm{~mm}$

Mesh bias effects were employed in the models to grade the elements' size, enabling to reduce the total number of elements but without compromising the accuracy. This was done by considering a more refined mesh near the adhesive layer and towards its edges, and a coarser mesh in the zones with less stress variations [28]. The elements' side dimensions in the adhesive layer for the XFEM simulations were $0.2 \times 0.2 \mathrm{~mm}$ along the bondline, i.e., only one element through-thickness was considered. The boundary conditions consisted of fixing the base edges to simulate gripping in the testing machine, applying symmetry at the middle of the specimen and pulling the curved adherends' edges in peel.

\subsection{XFEM Theory}

As an extension to the conventional FEM, the XFEM is based on the integration of enrichment functions in the FEM formulation [29]. These functions allow modelling the displacement jump between crack faces that occur during the propagation of a crack. The Abaqus ${ }^{\circledR}$ XFEM formulation enables the user to create a pre-crack, or it can initiate cracks in uncracked regions by using initiation criteria. In this last scenario, considered in this work, damage initiates and subsequently propagates during the simulation at regions experiencing stresses and/or strains higher than the corresponding limiting values. Six crack initiation criteria are available in Abaqus ${ }^{\circledR}$. The MAXPS (maximum principal stress) and MAXPE (maximum principal strain) criteria are based on the introduction of the following functions (by the respective order):

$$
f=\left\{\frac{\left\langle\sigma_{\max }\right\rangle}{\sigma_{\max }^{0}}\right\} \quad \text { or } \quad f=\left\{\frac{\left\langle\varepsilon_{\max }\right\rangle}{\varepsilon_{\max }^{0}}\right\}
$$

$\sigma_{\max }$ and $\sigma_{\max }^{0}$ represent the current and allowable maximum principal stress. The Macaulay brackets indicate that a purely compressive stress state does not induce damage. $\varepsilon_{\max }$ and $\varepsilon_{\max }^{0}$ represent the current and allowable maximum principal strain. Crack growth for the MAXPS and MAXPE criteria is software defined as orthogonal to the maximum principal stress/strain direction. As a result of this, and due to the inherent mixed-mode loading of these joints, the crack grows fast towards the adherends. For these two criteria, the maximum load $\left(P_{\mathrm{m}}\right)$ estimation was thus considered to take place at the time of first cracking in the adhesive layer. The MAXS (maximum nominal stress) and MAXE (maximum nominal strain) criteria are represented by the following functions, respectively

$$
f=\max \left\{\frac{\left\langle t_{\mathrm{n}}\right\rangle}{t_{\mathrm{n}}^{0}}, \frac{t_{\mathrm{s}}}{t_{\mathrm{s}}^{0}}\right\} \text { or } f=\max \left\{\frac{\left\langle\varepsilon_{\mathrm{n}}\right\rangle}{\varepsilon_{\mathrm{n}}^{0}}, \frac{\varepsilon_{\mathrm{s}}}{\varepsilon_{\mathrm{s}}^{0}}\right\}
$$

$t_{\mathrm{n}}$ and $t_{\mathrm{s}}$ are the current normal and shear traction components to the cracked surface. $t_{\mathrm{n}}{ }^{0}$ and $t_{\mathrm{s}}{ }^{0}$ represent the respective limiting values. The strain parameters have identical significance. The quadratic nominal stress (QUADS) and quadratic nominal strain (QUADE) criteria are based on the introduction of the following functions, respectively

$$
f=\left\{\frac{\left\langle t_{\mathrm{n}}\right\rangle}{t_{\mathrm{n}}^{0}}\right\}^{2}+\left\{\frac{t_{\mathrm{s}}}{t_{\mathrm{s}}^{0}}\right\}^{2} \text { or } f=\left\{\frac{\left\langle\varepsilon_{\mathrm{n}}\right\rangle}{\varepsilon_{\mathrm{n}}^{0}}\right\}^{2}+\left\{\frac{\varepsilon_{\mathrm{s}}}{\varepsilon_{\mathrm{s}}^{0}}\right\}^{2}
$$

For the MAXS, MAXE, QUADS and QUADE criteria, the user can select between horizontal or vertical crack growth (in this work horizontal growth, i.e., along the adhesive layers' length, was selected). All the six aforementioned criteria are fulfilled, and damage initiates when $f$ reaches unity. For damage growth, the fundamental expression of the displacement vector $\mathbf{u}$, including the displacements enrichment, is written as [30]:

$$
\mathbf{u}=\sum_{i=1}^{N} N_{i}(x)\left[\mathbf{u}_{i}+H(x) \mathbf{a}_{i}\right]
$$

$N_{i}(x)$ and $\mathbf{u}_{i}$ relate to the conventional FEM formulation, corresponding to the nodal shape functions and nodal displacement vector linked to the continuous part of the formulation, respectively. The second term between brackets, $H(x) \mathbf{a} i$, is only active in the nodes for which any relating shape function is cut by the crack and can be expressed by the product of the nodal enriched degree of freedom vector 
including the mentioned nodes, $\mathrm{a} i$, with the associated discontinuous shape function, $H(x)$, across the crack surfaces. The method is based on the establishment of phantom nodes that subdivide elements cut by a crack and simulate separation between the newly created sub-elements. Propagation of a crack along an arbitrary path is made possible by the use of these phantom nodes that initially have exactly the same coordinates than the real nodes and that are completely constrained to the real nodes up to damage initiation. After being crossed by a crack, the element is partitioned in two sub-domains. The discontinuity in the displacements is made possible by adding phantom nodes superimposed to the original nodes. When an element cracks, each one of the two subelements will be formed by real nodes (the ones corresponding to the cracked part) and phantom nodes (the ones that no longer belong to the respective part of the original element). These two elements that have fully independent displacement fields replace the original one. Thus, the crack size increment for a given crack orientation is equal to the distance between the cracked element's edges. From this point, each pair of real/phantom node of the cracked element is allowed to separate according to a suitable damage law up to failure. At this stage, the real and phantom nodes are free to move unconstrained, simulating crack growth. A linear softening XFEM law was considered with an energetic failure power law criterion of the type:

$$
\left(\frac{G_{\mathrm{I}}}{G_{\mathrm{IC}}}\right)^{\alpha}+\left(\frac{G_{\mathrm{II}}}{G_{\mathrm{IIC}}}\right)^{\alpha}=1,
$$

in which $\alpha$ is the damage law exponent ( $\alpha=1$ for linear softening).

\section{RESULTS}

\subsection{Experimental Failure Modes}

All failures took place beginning with crack propagation at $x / L_{0}=0$ and growing towards the other edge. After failure, the fracture surfaces were inspected and cohesive failures were found for all adhesives and $t_{\mathrm{P} 2}$. However, in some cases, especially for the joints bonded with the Araldite ${ }^{\circledR}$ AV138, failure sometimes took place near one of the adherend/adhesive interfaces (figure 4 shows an example for the joints with $t_{\mathrm{P} 2}=2 \mathrm{~mm}$ ), so that visually it resembled an adhesive failure. However, careful surface inspection including optical microscope observations revealed that the adherends that at first hand suffered form an adhesive failure were actually covered by a thin layer of adhesive. These findings are consistent with previous observations on this particular adhesive [27]. The fracture surfaces for the joints bonded with Araldite ${ }^{\circledR} 2015$ and Sikaforce ${ }^{\circledR}$ 7752 were smoother, indicative of ductile fractures, with a clearer evidence of cohesive failures. L-part adherend plasticization was detected in all joints bonded with Araldite ${ }^{\circledR} 2015$ and $t_{\mathrm{P} 2}=1 \mathrm{~mm}$, and also with Sikaforce ${ }^{\circledR} 7752$ and $t_{\mathrm{P} 2}=1$ and $2 \mathrm{~mm}$, although for this last case it was under $0.1 \%$.

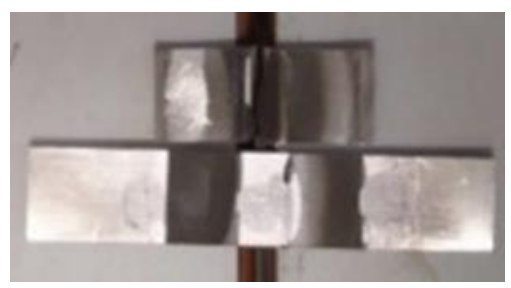

Fig. 4. Fracture surfaces for a T-joint bonded with Araldite ${ }^{\circledR} \mathrm{AV} 138$ and with $t_{\mathrm{P} 2}=2 \mathrm{~mm}$

\subsection{Experimental Strength}

The experimentally obtained $P_{\mathrm{m}}$ for the T-joints bonded with the three adhesives are presented in this Section. Figure 5 reports the average $P_{\mathrm{m}}$ vs. $t_{\mathrm{P} 2}$ curves, including the standard deviation of the experiments.

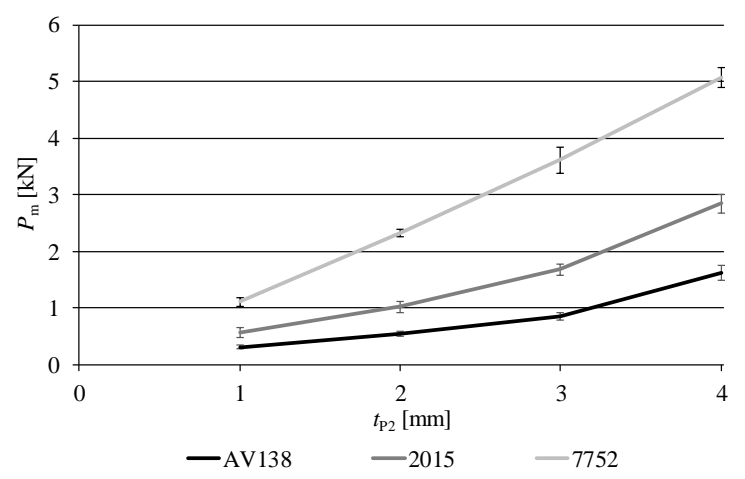

Fig. 5. Experimental $P_{\mathrm{m}}$ vs. $t_{\mathrm{P} 2}$ curves for the three adhesives

It can be found that $P_{\mathrm{m}}$ always increases, by a large amount, with $t_{\mathrm{P} 2}$, irrespectively of the adhesive. The two Araldite ${ }^{\circledR}$ adhesives show an increasing growth with $t_{\mathrm{P} 2}$, while Sikaforce ${ }^{\circledR} 7752$ has a marked linear evolution of the $P_{\mathrm{m}}$ vs. $t_{\mathrm{P} 2}$ curve. The percentile $P_{\mathrm{m}}$ increase for the T-joints with $t_{\mathrm{P} 2}=2,3$ and $4 \mathrm{~mm}$, over the T-joint with $t_{\mathrm{P} 2}=1 \mathrm{~mm}$, was respectively of $75.0 \%, 173.8 \%$ and $419.3 \%$ (Araldite ${ }^{\circledR}$ AV138), $81.2 \%, 197.8 \%$ and $403.7 \%$ (Araldite ${ }^{\circledR}$ 2015) and $110.9 \%, 227.1 \%$ and $358.6 \%$ (Sikaforce $^{\circledR} 7752$ ). Among adhesives, Sikaforce ${ }^{\circledR} 7752$ clearly outperforms the other two adhesives, despite being the less strong amongst the three adhesives (Table 1). The $P_{\mathrm{m}}$ improvement of the $\mathrm{T}$-joints bonded with this adhesive, over those bonded with the Araldite ${ }^{\circledR}$ $\mathrm{AV} 138$, ranges between $213.8 \%\left(t_{\mathrm{P} 2}=4 \mathrm{~mm}\right)$ and $328.0 \%\left(t_{\mathrm{P} 2}=2 \mathrm{~mm}\right)$. On the other hand, compared against the joints bonded with Araldite ${ }^{\circledR} 2015$, the $P_{\mathrm{m}}$ improvement varies between $78.5 \%\left(t_{\mathrm{P} 2}=4 \mathrm{~mm}\right)$ and $128.1 \%\left(t_{\mathrm{P} 2}=2 \mathrm{~mm}\right)$. It is also visible in figure 5 that $P_{\mathrm{m}}$ for the joints bonded with Araldite ${ }^{\circledR} 2015$ are 
higher than those with Araldite ${ }^{\circledR}$ AV138. In fact, depending on $t_{\mathrm{P} 2}, P_{\mathrm{m}}$ may almost double the ones obtained with Araldite $^{\circledR}$ AV138 adhesive, although this adhesive has higher strengths. The improvement is minimum for $t_{\mathrm{P} 2}=4 \mathrm{~mm}(78.4 \%)$ and maximum for $t_{\mathrm{P} 2}=3 \mathrm{~mm}(97.2 \%)$. These results show that, in a test geometry that is mainly loaded in peel, and which promotes stresses to be concentrated in small areas, flexible and ductile adhesives behave best. On the one hand, the flexibility tends to increase the area along which stresses are being transferred. On the other hand, the ductility permits plasticization of the adhesive at the stress concentration sites while the regions in the vicinity become loaded, resulting in an overall improved behaviour.

\subsection{XFEM Strength Prediction}

The XFEM initiation criteria described in Section 3.2 are evaluated against the experimental data, by directly comparing $P_{\mathrm{m}}$ with the experiments. As it was previously discussed, the use of the MAXS, MAXE, QUADS and QUADE criteria results in crack onset and growth parallel to the adhesive layer, while the MAXPS and MAXPE criteria lead to cracking perpendicular to the maximum principal stresses or strains, which subsequently makes the crack grow in the direction of the adherends. Figure 6 shows the $P_{\mathrm{m}}$ comparison for all $t_{\mathrm{P} 2}$ between the different XFEM initiation criteria and the experiments for the adhesives Araldite ${ }^{\circledR}$ AV138 (a), Araldite ${ }^{\circledR} 2015$ (b) and Sikaforce ${ }^{\circledR} 7752$ (c).

For the Araldite ${ }^{\circledR}$ AV138, the QUADS and MAXS criteria are closest to the experimental points, and the respective curves are practically overlapped in the figure. Averaged over the experiments, the maximum relative deviations were $+8.8 \%\left(t_{\mathrm{P} 2}=2 \mathrm{~mm}\right)$ and $+9.5 \%\left(t_{\mathrm{P} 2}=2 \mathrm{~mm}\right)$, respectively, for these two criteria. The MAXPS criterion revealed to be unsuited, in the manner that it was used, since $P_{\mathrm{m}}$ highly underestimates the tests (up to $-82.5 \%$ for $t_{\mathrm{P} 2}=1$ $\mathrm{mm}$ ). Oppositely to this behaviour, the strain-based criteria (QUADE, MAXE and MAXPE) overshoot the experimental data, with emphasis on the QUADE and MAXE criteria. The highest offsets for these criteria were $+113.3 \%$ (QUADE), $+117.3 \%$ (MAXE) and $+31.3 \%$ (MAXPE), in all cases for $t_{\mathrm{P} 2}=2 \mathrm{~mm}$. Qualitatively, the $P_{\mathrm{m}}$ predictions for Araldite $^{\circledR} 2015$ by the six criteria agree with those of Araldite ${ }^{\circledR}$ AV138. Thus, the QUADS and MAXS criteria are quite close to the experimental values, with a negligible difference between them. The maximum $P_{\mathrm{m}}$ deviations were, in both cases, obtained for $t_{\mathrm{P} 2}=4$ $\mathrm{mm}$, attaining -8.9\% (QUADS) and -8.6\% (MAXS).

The MAXPS criterion was offset up to $-81.3 \%$ $\left(t_{\mathrm{P} 2}=1 \mathrm{~mm}\right)$, whilst the maximum deviations for the strain-based criteria attained maximums of $+110.7 \%$ for both QUADE and $\operatorname{MAXE}\left(t_{\mathrm{P} 2}=1 \mathrm{~mm}\right)$, and $+55.2 \%$ the MAXPE criterion $\left(t_{\mathrm{P} 2}=2 \mathrm{~mm}\right)$. Finally, the results for Sikaforce ${ }^{\circledR} 7752$ were much alike those of the former adhesives although, in this case, even the QUADS and MAXS criteria showed bigger variations to the experimental $P_{\mathrm{m}}$ (up to $-13.3 \%$ for the QUADS, considering $t_{\mathrm{P} 2}=4 \mathrm{~mm}$, and $+13.3 \%$ for the MAXS, considering $t_{\mathrm{P} 2}=1 \mathrm{~mm}$ ). Identically, the curves for these two criteria overlap. Due to the aforementioned approximations, the MAXPS criterion showed $P_{\mathrm{m}}$ values much below the expected, with a maximum deviation of $-85.8 \%\left(t_{\mathrm{P} 2}=3 \mathrm{~mm}\right)$. The strain-based criteria was significantly over the predicted $P_{\mathrm{m}}$, in line with the previous adhesives. The maximum offsets, all by excess, were $+197.8 \%$ for the QUADE $\left(t_{\mathrm{P} 2}=2\right.$ $\mathrm{mm}),+214.7 \%$ for the $\operatorname{MAXE}\left(t_{\mathrm{P} 2}=4 \mathrm{~mm}\right)$ and $+160.5 \%$ for the MAXPE $\left(t_{\mathrm{P} 2}=2 \mathrm{~mm}\right)$.

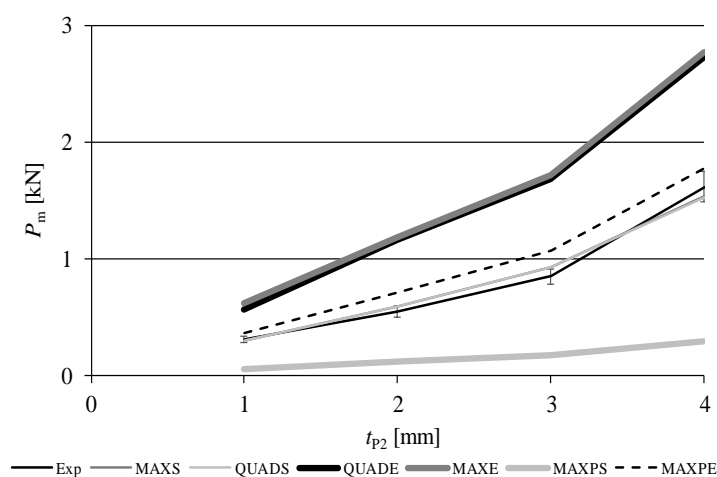

a)

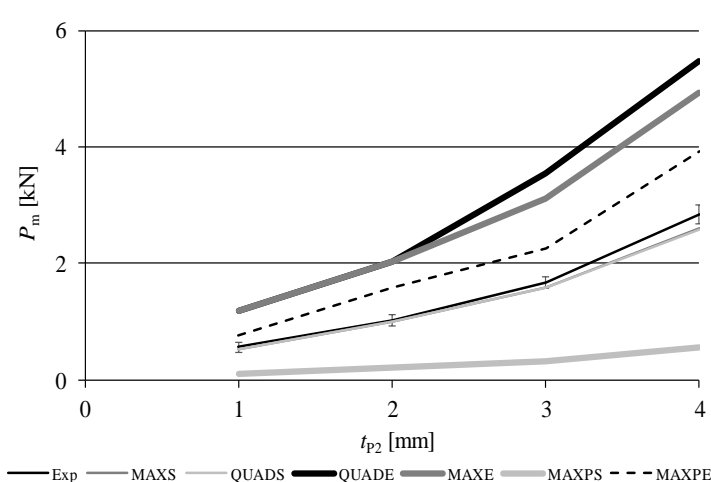

b)

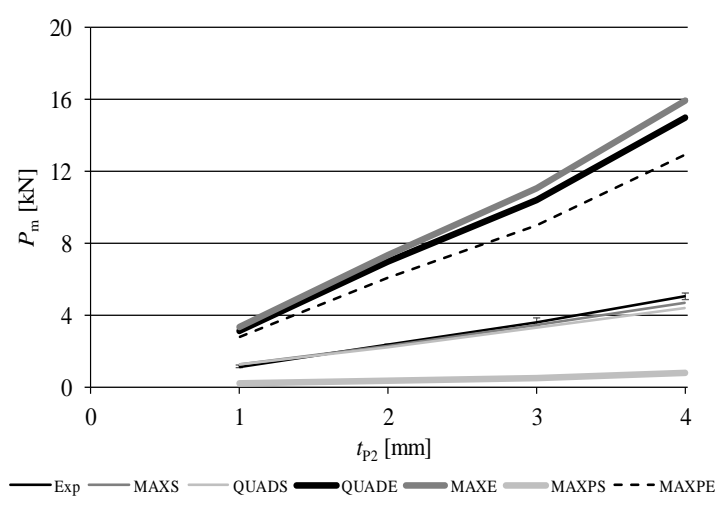

Fig. 6. Experimental and numerical $P_{\mathrm{m}}$ comparison, considering different XFEM initiation criteria, for the T-joints bonded with Araldite ${ }^{\circledR}$ AV138 a) Araldite ${ }^{\circledR}$ 2015; b) and Sikaforce ${ }^{\circledR} 7752$ c) 
It was shown in a previous work [23] that damage initiation is ruled by the adhesive layer's stresses rather than the strains (which also vary by a large amount between adhesives). On the other hand, using strain-based criteria can result in major deviations to the real joint behaviour, with an over prediction tendency. This is why the QUADS and MAXS criteria generally work very well. The QUADE and MAXE criteria, being based on strains, naturally present wrong $P_{\mathrm{m}}$ results and should not be considered in the design process of bonded joints. The MAXPS and MAXPE criteria, due to their intrinsic formulation, are unable to promote a realistic damage growth path, since the crack growth direction is ruled by the maximum principal stresses or strains, in a sense that crack initiates and grows perpendicularly to the principal directions. As a result, adherend detaching by the adhesive through all the adhesive layers is rendered unfeasible because the mixed-mode loading induced in the adhesive results in short crack growth in the adhesive before the crack hits the adherend interface. Since $P_{\mathrm{m}}$ was assessed by the damage initiation load, i.e., at the time the first crack occurs in the model, the results do not match the real joint behaviour.

\section{CONCLUSIONS}

This work presented an experimental and numerical assessment of the behaviour of adhesively-bonded Tjoints between aluminium adherends, considering different geometric conditions $\left(t_{\mathrm{P} 2}\right)$ and adhesives with different characteristics with respect to the strength and ductility. The experimental analysis showed that, for the particular joints conditions tested, i.e., a predominantly peel loading with major peak stresses, the most ductile although less strong Sikaforce ${ }^{\circledR} 7752$ is the one that presents better results for all $t_{\mathrm{P} 2}$. Increasing $t_{\mathrm{P} 2}$ highly increased $P_{\mathrm{m}}$ for all adhesives. The XFEM analysis applied to the initiation criterion enabled to conclude that, for all the adhesives, the QUADS and MAXS criteria were the most adequate. The MAXPS criterion was inadequate, in view of the simplification taken to estimate $P_{\mathrm{m}}$. All strain-based criteria (QUADE, MAXE and MAXPE) overshot $P_{\mathrm{m}}$ by a large amount for the three adhesives, and should not be considered as well.

\section{REFERENCES}

[1] Petrie E.M., Handbook of adhesives and sealants, New York: McGraw-Hill, 2000.

[2] Akpinar S., The strength of the adhesively bonded step-lap joints for different step numbers, Composites Part B: Engineering, vol. 67, 2014, pp. 170-178.

[3] Di Bella G., Borsellino C., Pollicino E., Ruisi V. F., Experimental and numerical study of composite T-joints for marine application, International Journal of Adhesion and Adhesives, vol. 30(5), 2010, pp. 347-358

[4] Trask R. S., Hallett S. R., Helenon F. M. M., Wisnom M. $\mathbf{R} .$, Influence of process induced defects on the failure of composite T-joint specimens, Composites Part A: Applied Science and Manufacturing, vol. 43(4), 2012, pp. 748-757.
[5] Bianchi F., Koh T.M., Zhang X., Partridge I.K., Mouritz A.P., Finite element modelling of z-pinned composite T-joints, Composites Science and Technology, vol. 73, 2012, pp. 48-56.

[6] Burns L. A., Mouritz A. P., Pook D., Feih S., Bio-inspired design of aerospace composite joints for improved damage tolerance, Composite Structures, vol. 94(3), 2012, pp. 995-1004.

[7] Yang T., Zhang J., Mouritz A. P., Wang C. H., Healing of carbon fibre-epoxy composite $T$-joints using mendable polymer fibre stitching, Composites Part B: Engineering, vol. 45(1), 2013, pp. 1499-1507.

[8] Duan K., Hu X., Mai Y. W., Substrate constraint and adhesive thickness effects on fracture toughness of adhesive joints, Journal of Adhesion Science and Technology, vol. 18(1), 2004, pp. 39-53.

[9] Panigrahi S.K., Pradhan B., Three Dimensional Failure Analysis and Damage Propagation Behavior of Adhesively Bonded Single Lap Joints in Laminated FRP Composites, Journal of Reinforced Plastics and Composites, vol. 26(2), 2007, pp. 183-201.

[10] Weißgraeber P., Becker W., Crack Initiation at Weak Stress Singularities - Finite Fracture Mechanics Approach, Procedia Materials Science, vol. 3, 2014, pp. 153-158.

[11] da Silva L.F.M., Campilho R.D.S.G., Advances in numerical modelling of adhesive joints, Heidelberg: Springer, 2012.

[12] Yang Q.D., Thouless M.D., Mixed-mode fracture analyses of plastically-deforming adhesive joints, International Journal of Fracture, vol. 110(2), 2001, pp. 175-187.

[13] Khoramishad H., Crocombe A. D., Katnam K. B., Ashcroft I. A., Predicting fatigue damage in adhesively bonded joints using a cohesive zone model, International Journal of Fatigue, vol. 32(7), 2010, pp. 1146-1158.

[14] Daudeville L., Ladevèze P., A damage mechanics tool for laminate delamination, Composite Structures, vol. 25(1-4), 1993, pp. 547-555.

[15] Voyiadjis G. Z. Kattan P. I., Damage Mechanics, New York: Marcell Dekker, 2005.

[16] Raghavan, P., Ghosh S., A continuum damage mechanics model for unidirectional composites undergoing interfacial debonding, Mechanics of Materials, vol. 37(9), 2005, pp. 955-979.

[17] Imanaka M., Hamano T., Morimoto A., Ashino R., Kimoto M., Fatigue damage evaluation of adhesively bonded butt joints with a rubber-modified epoxy adhesive, Journal of Adhesion Science and Technology, vol. 17(7), 2003, pp. 981-994.

[18] Wahab M. M. A., Ashcroft I. A., Crocombe A. D., Shaw S. J., Prediction of fatigue thresholds in adhesively bonded joints using damage mechanics and fracture mechanics, Journal of Adhesion Science and Technology, vol. 15(7), 2001, pp. 763-781.

[19] Mohammadi S., Extended finite element method for fracture analysis of structures, 2008, New Jersey, USA: Blackwell Publishing.

[20] Moës N., Dolbow J., Belytschko T., A finite element method for crack growth without remeshing, International Journal for Numerical Methods in Engineering, vol. 46(1), 1999, pp. 131-150.

[21] Mubashar A., Ashcroft I. A., Crocombe A. D., Modelling damage and failure in adhesive joints using a combined XFEMcohesive element methodology, The Journal of Adhesion, vol. 90(8), 2014, pp. 682-697.

[22] Stuparu F., Constantinescu D. M., Apostol D. A., Sandu M., A Combined Cohesive Elements-XFEM Approach for Analyzing Crack Propagation in Bonded Joints. The Journal of Adhesion, vol. 92(7-9), 2016, pp. 535-552.

[23] Campilho R. D. S. G., Banea M. D., Pinto A. M. G., da Silva L. F. M., de Jesus A. M. P., Strength prediction of singleand double-lap joints by standard and extended finite element modelling, International Journal of Adhesion and Adhesives, vol. 31(5), 2011, pp. 363-372.

[24] Campilho R. D. S. G., Banea M. D., Neto J. A. B. P., da Silva L. F. M., Modelling adhesive joints with cohesive zone models: effect of the cohesive law shape of the adhesive layer, International Journal of Adhesion and Adhesives, vol. 44, 2013, pp. 48-56.

[25] Faneco T., Campilho R., Silva F., Lopes R., Strength and Fracture Characterization of a Novel Polyurethane Adhesive for the Automotive Industry, Journal of Testing and Evaluation, vol. 45(2), 2017, pp. 398-407.

[26] Campilho R. D. S. G., Pinto A. M. G., Banea M. D., Silva R. F., da Silva L. F. M., Strength Improvement of Adhesively- 
Bonded Joints Using a Reverse-Bent Geometry, Journal of Adhesion Science and Technology, vol. 25(18), 2011, pp. 23512368.

[27] Nunes S. L. S., Campilho R. D. S. G., da Silva F. J. G., de Sousa C. C. R. G., Fernandes T. A. B., Banea M. D., da Silva L. F. M., Comparative failure assessment of single and double-lap joints with varying adhesive systems, The Journal of Adhesion, vol. 92, 2016, pp. 610-634.

[28] Fernandes T. A. B., Campilho R. D. S. G., Banea M. D., da
Silva L. F. M., Adhesive selection for single lap bonded joints: Experimentation and advanced techniques for strength prediction, The Journal of Adhesion, vol. 91(10-11), 2015, pp. 841-862.

[29] Pike M. G., Oskay C., XFEM modeling of short microfiber reinforced composites with cohesive interfaces, Finite Elements in Analysis and Design, vol. 106, 2015, pp. 16-31.

[30] *** Abaqus@, Documentation of the software Abaqus®. 2013: Dassault Systèmes. Vélizy-Villacoublay 